\title{
Synthesis, Structural Characterization, and Antimicrobial Activity Evaluation of New Binuclear Niobium(V) Tartrate Complexes with Biologically Important Drugs
}

\author{
H. D. Revanasiddappa, ${ }^{1}$ B. Vijaya, ${ }^{2}$ L. Shivakumar, ${ }^{1}$ and K. Shiva Prasad ${ }^{1}$ \\ ${ }^{1}$ Department of Chemistry, University of Mysore, Manasagangotri, Mysore 570006, India \\ ${ }^{2}$ Department of Chemistry, University of BDT College of Engineering, Davanagere University, Davanagere 577004, India
}

Correspondence should be addressed to H. D. Revanasiddappa; hdrevanasiddappa@yahoo.com

Received 31 October 2012; Accepted 27 November 2012

Academic Editors: A. Karadag, A. Lehtonen, and M. Pellei

Copyright (C) 2013 H. D. Revanasiddappa et al. This is an open access article distributed under the Creative Commons Attribution License, which permits unrestricted use, distribution, and reproduction in any medium, provided the original work is properly cited.

\begin{abstract}
The new binuclear niobium $(\mathrm{V})$ complexes of the type $\left[\left[\mathrm{NbO}(\mathrm{L}) \mathrm{C}_{4} \mathrm{H}_{4} \mathrm{O}_{6}\right]_{2} \mathrm{C}_{4} \mathrm{H}_{4} \mathrm{O}_{6}\right]$ (where $\mathrm{L}=\mathrm{DMH}, \mathrm{IMH}, \mathrm{IPH}, \mathrm{FPH}$, TMT) were prepared with biologically important drugs and characterized by using elemental analysis; IR, ${ }^{1} \mathrm{H}-\mathrm{NMR}$, and UV-Vis spectral studies, and thermogravimetric analysis. The molar conductance measurement of all the complexes in DMF solution corresponds to $1: 1$ electrolytic nature. All complexes were of the pure diamagnetic character and were found to have six-coordinate octahedral geometry. The antimicrobial activity of these complexes has been screened against two Gram-positive and two Gram-negative bacteria. Antifungal activity against two different fungi has been evaluated and compared with controls. All the complexes inhibit the growth of both Gram-positive and Gram-negative bacteria to a competent level.
\end{abstract}

\section{Introduction}

Metal ions play a vital role in a vast number of biological processes. Niobium ions form complex species with virtually all types of neutral and anionic donors. Niobium and its compounds have a broad spectrum of applications. They are used for the fabrication of special materials for microelectronics and optics, superconductors, refractory materials, catalysts, and alloys [1-5]. As an important alloy element in steels, niobium can greatly affect the properties of a sample, such as the intensity at high temperature, the ability of tarnish resistance, and temper brittleness [6,7]. Niobium steels are valuable constructive materials for the chemical and nuclear industries, jet and rocket engines, gas pipelines, and turbines [8]. The chemistry of the early transition metal peroxo complexes has received special attention due to their importance in a variety of biological, pharmaceutical, and industrial processes [9]. Uses of metal ions in therapeutic agents are known to accelerate drug action, and their efficacy is enhanced upon the coordination with a metal ion [10]. The antimicrobial properties of metal complexes have been recognized for centuries and have represented some of the most fundamental breakthroughs in medicinal history [11]. However, $\mathrm{Nb}(\mathrm{V})$ complexes have been limitedly studied as the biocidal agents $[12,13]$. Thus, we intended to study the ability of niobium complexes as good antimicrobial agents.

The present work describes the preparation of new niobium $(\mathrm{V})$ tartrate complexes containing active pharmaceutical drugs (Figure 1). The isolated complexes were studied via elemental analysis; IR, ${ }^{1} \mathrm{H}-\mathrm{NMR}$, and UV spectroscopies; and TGA. In view of the biological activity of the complexes and diverse coordinating ability of the ligands, we were provoked to study the niobium $(\mathrm{V})$ complexes of nitrogenbased ligands against microbial strains, namely, E. coli, $S$. aureus, $P$. aeruginosa, and $B$. subtilis, and fungal strains $A$. flavus and $A$. niger were undertaken to study their role as microbial compounds.

\section{Experimental}

2.1. Materials. The ligands IPH (isothipendyl hydrochloride, SKF Ltd., India), IMH (imipramine hydrochloride, Sun Pharmaceuticals Ltd., India), DMH (desipramine hydrochloride, 


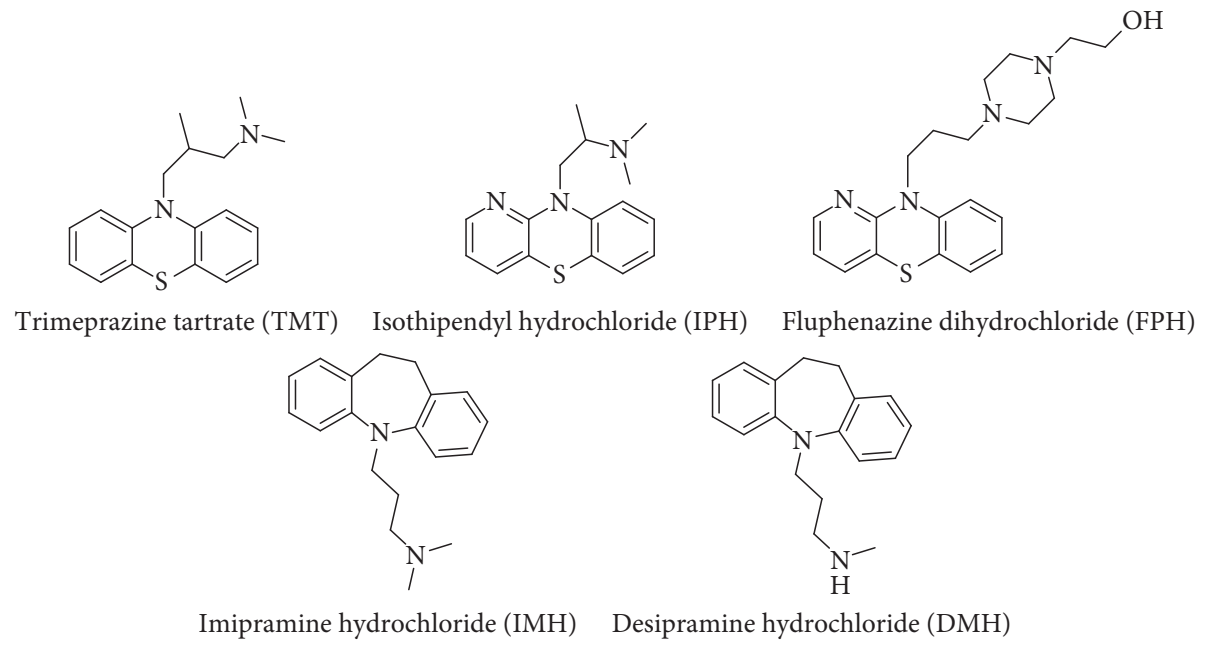

FIgURE 1: Structure of the pharmaceutical drugs.

Smith Kline and Beecham Ltd., India), FPH (fluphenazine dihydrochloride, SKF Ltd., India), and TMT (trimeprazine tartrate, Intas Laboratories Ltd., India), were received from pharmaceutical industries as gift samples and used as received. Among the solvents employed, DMF and DMSO were of spectroscopic grade and remaining solvents were of AR grade.

2.2. Preparation of Niobium(V) Solution. Niobium(V) solution was prepared [14] by fusion of $0.05 \mathrm{~g}$ of niobium pentoxide with $2 \mathrm{~g}$ of potassium pyrosulphate in a silica crucible and leaching the mass with $20 \mathrm{~mL}$ of $10 \%$ tartaric acid solution. The solution was then diluted to $100 \mathrm{~mL}$ using water, and this solution was used for the preparation of complexes. Fresh solutions were prepared whenever required.

2.3. Physical Measurements. FTIR spectra for samples were recorded using Jasco FT-IR-4100 spectrometer. ${ }^{1} \mathrm{H}-\mathrm{NMR}$ spectra were recorded in DMSO- $\mathrm{d}_{6}$ on AMX-400 FT-NMR spectrometer. Electronic spectra of the complexes in the UVVisible region (200-900 $\mathrm{nm}$ ) were measured using a Jasco UVIDEC-610 double-beam spectrophotometer with quartz cells. Electrical conductance measurements of the prepared complexes were done using an Elico CM-180 conductometer. Melting points were determined in an open capillary tube on Mel-temp apparatus. Magnetic susceptibility data in the room temperature were obtained from Gouy method using $\mathrm{Hg}\left[\mathrm{Co}(\mathrm{SCN})_{4}\right]$ as a calibrant. The TG and DTA patterns of the complexes were recorded on a Perkin Elmer US TGA-7 analyzer in the atmosphere of air. The carbon, hydrogen, and nitrogen contents of the complexes were determined by CHNS analyzer. Tartrate was determined volumetrically by using chloramines-T. Niobium was estimated gravimetrically by direct ignition to $\mathrm{Nb}_{2} \mathrm{O}_{5}$ [15].

2.4. Antibacterial Activity. The in vitro biocidal activities of the ligands and their niobium(V) complexes were tested against four bacteria namely, S. aureus, E. coli, P. aeraginosa and B. subtilius by disk diffusion method [16].

The pure cultures of these organisms were obtained from the Department of Biotechnology, Bapuji Institute of Engineering and Technology, Davangere. The organisms used in the compounds were subcultured into sterile nutrient broth. After incubating the same organisms at $37^{\circ} \mathrm{C}$ for $3 \mathrm{~h}$, the growth thus obtained was used as inoculums for the tests. Nutrient agar $\left(28 \mathrm{gL}^{-1}\right)$ and nutrient broth were sterilized in conical flask of suitable capacity by autoclaving at $15 \mathrm{lb}$ pressure for $30 \mathrm{~min}$. The agar medium was melted on water bath and cooled to $45^{\circ} \mathrm{C}$. To the $20-25 \mathrm{~mL}$ molten agar $0.5-0.7 \mathrm{~mL}$ of 3 -h-old sub culture was added aseptically, mixed well by gentle shaking, and allowed to attain room temperature in Petri dishes. The sterilized filter paper disks (Whatman 41) were loaded with known volume of the test compound of known strength using micropipette to get the disk of desired concentration. The disks are placed over the growth media seeded with microorganisms, left for diffusion, and incubated at $37 \pm 2^{\circ} \mathrm{C}$ for $24 \mathrm{~h}$. The experiment is carried out with four replicates for each concentration. The antibiotic chloramphenicol was also screened under similar conditions for comparison as a standard, and the solvent DMSO was also put to know the activity.

2.5. Antifungal Activity. Antifungal activity of the test compounds was determined against two fungi, A. flavus and $A$. niger, by Bateman poisoned food technique [17]. These fungi were cultured for seven days on Czapek's agar in sterilized petri dishes under $12 / 12 \mathrm{~h}$ light and darkness. The ligand and its metal complexes dissolved in DMSO were added to $10-15 \mathrm{~mL}$ of sterilized media to achieve different concentrations at $35 \pm 2^{\circ} \mathrm{C}$ and allowed the media for solidification. The test fungi were taken as $2 \mathrm{~mm}$ disks from 10-day-old pure colonies and placed in the petri plates containing Czapek's agar nutritive medium. The experiments were carried out in four replicates per treatment, and incubation was carried 
TABLE 1: Physical analytical and molar conductance data of niobium(V) complexes.

\begin{tabular}{lccccc}
\hline \multirow{2}{*}{ Complex } & $\mathrm{C}$ & $\mathrm{H}$ & $\mathrm{N}$ & $\mathrm{S}$ & \multirow{2}{*}{$\mathrm{Ohm}^{-1} \mathrm{~cm}^{2} \mathrm{~mol}^{-1}$} \\
\hline \multirow{2}{*}{ (1) $\left[\mathrm{NbO}(\mathrm{DM}) \mathrm{C}_{4} \mathrm{H}_{4} \mathrm{O}_{6}\right]_{2} \mathrm{C}_{4} \mathrm{H}_{4} \mathrm{O}_{6}$} & 47.32 & 4.64 & 4.52 & - & 81 \\
\hline \multirow{2}{*}{ (2) $\left[\mathrm{NbO}(\mathrm{IM}) \mathrm{C}_{4} \mathrm{H}_{4} \mathrm{O}_{6}\right]_{2} \mathrm{C}_{4} \mathrm{H}_{4} \mathrm{O}_{6}$} & $(48.29)$ & $(4.69)$ & $(4.69)$ & & \multirow{2}{*}{83} \\
\hline \multirow{2}{*}{ (3) $\left[\mathrm{NbO}(\mathrm{IP}) \mathrm{C}_{4} \mathrm{H}_{4} \mathrm{O}_{6}\right]_{2} \mathrm{C}_{4} \mathrm{H}_{4} \mathrm{O}_{6}$} & $(49.78$ & 4.84 & 4.59 & - & 78 \\
\hline (4) $\left[\mathrm{NbO}(\mathrm{FP}) \mathrm{C}_{4} \mathrm{H}_{4} \mathrm{O}_{6}\right]_{2} \mathrm{C}_{4} \mathrm{H}_{4} \mathrm{O}_{6}$ & 42.22 & $(4.91)$ & $(4.58)$ & & 7.04 \\
\hline (5) $\left[\mathrm{NbO}(\mathrm{TM}) \mathrm{C}_{4} \mathrm{H}_{4} \mathrm{O}_{6}\right]_{2} \mathrm{C}_{4} \mathrm{H}_{4} \mathrm{O}_{6}$ & $(42.89)$ & $(4.06)$ & $(6.82)$ & $(5.19)$ & 77 \\
\hline
\end{tabular}

out at $22 \pm 2^{\circ} \mathrm{C}$ under $12 / 12$ light and darkness. The radical growth of the colony was recorded after $96 \mathrm{~h}$ of incubation.

2.6. Synthesis of Complexes. An ethanolic solution of corresponding ligands (each $50 \mathrm{~mL}$ of $4 \mathrm{mmol}$ ) was added to an aqueous solution of $3 \mathrm{mmol}$ of niobioum(V) slowly with constant stirring. The solid complexes were precipitated immediately. The solid complex was dried in vacuo over fused $\mathrm{CaCl}_{2}$ (yield: $55 \%-62 \%$ ).

\section{Result and Discussion}

3.1. Physical Properties. All the newly prepared complexes are coloured, nonhygroscopic, and stable at room temperature for long periods. They do not possess sharp melting points $\left(>300^{\circ} \mathrm{C}\right)$. The complexes are insoluble in water and other common organic solvents such as ethanol, methanol, and acetone but are soluble in DMF and DMSO. Analytical data of the complexes are given in Table 1. The data corresponds to the formula $\left[\mathrm{NbO}(\mathrm{L})\left(\mathrm{C}_{4} \mathrm{H}_{4} \mathrm{O}_{6}\right)\right]_{2} \mathrm{C}_{4} \mathrm{H}_{4} \mathrm{O}_{6}$.

The molar conductance of all the complexes for $10^{-3} \mathrm{M}$ solution in DMF at room temperature was found to be in the range of $77-84 \mathrm{Ohm}^{-1} \mathrm{~cm}^{2} \mathrm{~mol}^{-1}$ (Table 1) showing thereby $1: 1$ electrolytic nature of the complexes. This is consistent with the stoichiometry assumed for the complexes on the basis of analytical data. The magnetic susceptibility measurements carried out at room temperature were found to be diamagnetic. Indeed all the niobium $(\mathrm{V})$ complexes reported in the literature are diamagnetic [18].

3.2. Electronic Spectra. The electronic spectra of the niobium complexes in DMF show no absorption peaks in the visible region. The free ligands show sharp band in the $35714-38461 \mathrm{~cm}^{-1}$ region, while their corresponding complexes exhibit sharp peaks in the $34722-37037 \mathrm{~cm}^{-1}$ region. This may be assigned to $\pi \rightarrow \pi^{*}$ transition. A weak band in the $32051-32679 \mathrm{~cm}^{-1}$ region present in the spectra of the ligands is shifted towards a higher-energy region $\left(32462-3112 \mathrm{~cm}^{-1}\right)$ in the spectra of their complexes attributable to $n \rightarrow \pi^{*}$ transitions. The results obtained in the electronic spectra of the complexes are presented in Table 2.

3.3. IR Spectra. The major infrared spectral frequencies of the ligands and the selected IR data of their niobium(V) complexes are enumerated in Table 3. In ligands, the group $\mathrm{R}_{3} \mathrm{NH}^{+}$interacts with $\mathrm{Cl}^{-}$giving rise to a broad band in the region $2700-2300 \mathrm{~cm}^{-1}$ [14]. In the IR spectra of the corresponding niobium $(\mathrm{V})$ complexes, these bands are absent indicating that the tertiary nitrogen atom of the side chain is involved in coordination to the metal ion. It was pointed out that the heterocyclic nitrogen atom attached to the alkyl side chain gives rise to a characteristic broad band in the $2970-2830 \mathrm{~cm}^{-1}$ region. In the spectra of the corresponding complexes, these bands are either absent or shifted to a higher frequency $\left(\Delta v=10-30 \mathrm{~cm}^{-1}\right)$ indicating that the heterocyclic nitrogen atom is coordinated to the metal ion. In aromatic derivatives, $v$ (CSC) generally appears as a sharp band around $750 \mathrm{~cm}^{-1}$ region [19]. In the studied niobium $(\mathrm{V})$ complexes, it has been found that there is no change in $v(\mathrm{CSC})$ supporting the noncoordination of heterocyclic sulphur atom. The bands occurring at around $1550 \mathrm{~cm}^{-1}$ and at $740 \mathrm{~cm}^{-1}$ in IPH are due to $v(\mathrm{C}=\mathrm{N})$ and $v(\mathrm{C}-\mathrm{S})$ vibrations $[20,21]$, respectively. The $v(\mathrm{C}=\mathrm{N})$ bands present at 1550 and $740 \mathrm{~cm}^{-1}$ remain at the same position in the spectra of the complexes suggesting the noninvolvement of the pyridine ring nitrogen and heterocyclic sulphur atom of the ligand in bonding with niobium(V) ion.

The coordination of bidentate tartrate is confirmed by the bands at $1710-1680 \mathrm{~cm}^{-1} v(\mathrm{COO})$ and at $1410-1380 \mathrm{~cm}^{-1} v(\mathrm{COO})$ [22]. Bands observed in the $495-475 \mathrm{~cm}^{-1}$ region in the spectra of the complexes correspond to the $\mathrm{Nb}-\mathrm{O}-\mathrm{Nb}$. Presence of $v(\mathrm{Nb}-\mathrm{O})$ modes has been excluded because of the absence of peaks in the $560-540 \mathrm{~cm}^{-1}$ region. These complexes also exhibit two bands at $625-610$ and at $480-460 \mathrm{~cm}^{-1}$ due to antisymmetric vibrations of the $\mathrm{Nb}-\mathrm{O}-\mathrm{Nb}$ bridge bond, respectively. Bands observed at $3100-3000 \mathrm{~cm}^{-1}$ region in the spectra of phenothiazine ligands as well as their niobium $(\mathrm{V})$ complexes 
TABLE 2: Electronic spectral bands of niobium(V) complexes.

\begin{tabular}{|c|c|c|c|c|}
\hline Ligand & Electronic spectral bands, $\mathrm{cm}^{-1}$ & Complex & Electronic spectral bands, $\mathrm{cm}^{-1}$ & Assignment \\
\hline \multirow{2}{*}{$\mathrm{DMH}$} & 37594 & \multirow{2}{*}{1} & 38168 & $\pi \rightarrow \pi^{*}$ \\
\hline & 32051 & & 32679 & $n \rightarrow \pi^{*}$ \\
\hline \multirow{2}{*}{ IMH } & 37735 & \multirow{2}{*}{2} & 38461 & $\pi \rightarrow \pi^{*}$ \\
\hline & 32679 & & 33112 & $n \rightarrow \pi^{*}$ \\
\hline \multirow{2}{*}{ IPH } & 37313 & \multirow{2}{*}{3} & 34722 & $\pi \rightarrow \pi^{*}$ \\
\hline & 32467 & & 32894 & $n \rightarrow \pi^{*}$ \\
\hline \multirow{2}{*}{ FPH } & 37037 & \multirow{2}{*}{4} & 35714 & $\pi \rightarrow \pi^{*}$ \\
\hline & 32573 & & 32671 & $n \rightarrow \pi^{*}$ \\
\hline \multirow{2}{*}{ TMT } & 35714 & \multirow{2}{*}{5} & 36496 & $\pi \rightarrow \pi^{*}$ \\
\hline & 32051 & & 32462 & $n \rightarrow \pi^{*}$ \\
\hline
\end{tabular}

TABLE 3: Characteristic IR bands $\left(\mathrm{cm}^{-1}\right)$ of the ligands and their niobium(V) complexes.

\begin{tabular}{|c|c|c|c|c|c|c|c|c|}
\hline Ligands/complex & $v\left(\mathrm{~N}-\mathrm{CH}_{3}\right)$ & $v\left(\mathrm{~N}-\mathrm{CH}_{2}\right)$ Hetero & $v_{\mathrm{as}}(\mathrm{OCO})$ & $v_{\mathrm{s}}(\mathrm{OCO})$ & $v_{\text {as }}(\mathrm{Nb}-\mathrm{O})$ & $v_{s}(\mathrm{Nb}-\mathrm{O})$ & $v(\mathrm{Nb}-\mathrm{N})$ & $v(\mathrm{C}-\mathrm{S})$ \\
\hline $\mathrm{DMH}$ & $\begin{array}{c}v\left(\mathrm{NH}-\mathrm{CH}_{3}\right) \\
2830\end{array}$ & 2915 & - & - & - & - & - & - \\
\hline 1 & - & - & 1710 & 1400 & 620 & 470 & 370 & - \\
\hline $\mathrm{IMH}$ & 2655 & 2923 & - & - & - & - & - & - \\
\hline 2 & - & - & 1690 & 1390 & 618 & 466 & 390 & - \\
\hline $\mathrm{IPH}$ & 2560 & 2905 & - & - & - & - & - & 740 \\
\hline 3 & - & - & 1705 & 1405 & 610 & 460 & 380 & 740 \\
\hline FPH & 2585 & 2895 & - & - & - & - & - & 760 \\
\hline 4 & - & - & 1695 & 1395 & 622 & 475 & 375 & 760 \\
\hline TMT & 2530 & 2850 & - & - & - & - & - & 755 \\
\hline 5 & - & - & 1705 & 1385 & 625 & 485 & 390 & 755 \\
\hline
\end{tabular}

may be assigned to $v(\mathrm{C}-\mathrm{H})$ stretching of the aromatic ring system. The far IR spectra of studied niobium(V) complexes exhibit medium intense bands in the region $390-350 \mathrm{~cm}^{-1}$ assigned to $v(\mathrm{Nb}-\mathrm{N})$ modes [23]. This confirms the participation of the nitrogen atom in coordination.

3.4. ${ }^{1} \mathrm{H}$-NMR Studies. The ${ }^{1} \mathrm{H}-\mathrm{NMR}$ spectra of the ligand IPH and its complex are presented in Figure 2. The ligands IPH and TMT exhibit a doublet at around $\delta 1.3 \mathrm{ppm}$, which is assigned to $-\mathrm{CH}-\mathrm{CH}_{3}$, whereas the IMH, IPH, and TMT exhibit a sharp signal (singlet) at around $\delta 2.68 \mathrm{ppm}$ due to tertiary nitrogen attached to alkyl group, that is, $-\mathrm{N}-\mathrm{CH}_{3}$. The multiplet centered at $\delta 3.58-3.52 \mathrm{ppm}$ is attributed to $-\mathrm{N}-\mathrm{CH}_{2}$ in all the ligands. The other multiplet at $\delta$ $6.78-7.82 \mathrm{ppm}$ in ligands is due to aromatic protons. The $\mathrm{DMH}$ showed a signal at $\delta 9.76 \mathrm{ppm}$ that is assignable to $-\mathrm{NH}$ proton.

The $\mathrm{Nb}(\mathrm{V})$ complexes exhibit signals at around $\delta 2.8$ and $\delta 3.64 \mathrm{ppm}$ that indicate the shift of alkyl protons attached to tertiary nitrogen, thereby suggesting the involvement of tertiary nitrogen in coordination with $\mathrm{Nb}(\mathrm{V})$ ion. Thus ${ }^{1} \mathrm{H}$ NMR supports the conclusion drawn on the basis of IR data regarding the involvement of tertiary nitrogen atoms in bonding with $\mathrm{Nb}(\mathrm{V})$ ion. In the ${ }^{1} \mathrm{H}$ NMR spectra of

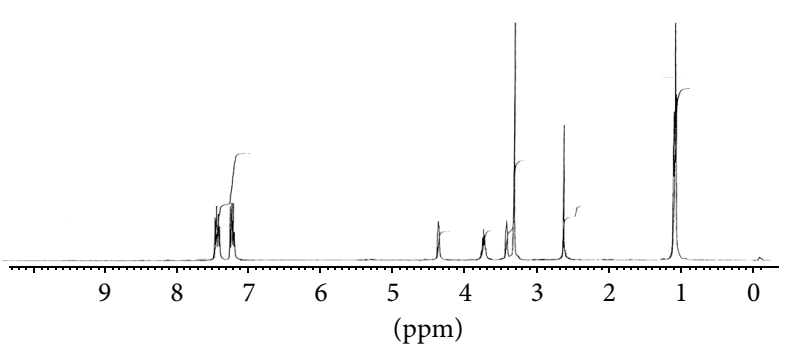

(a)

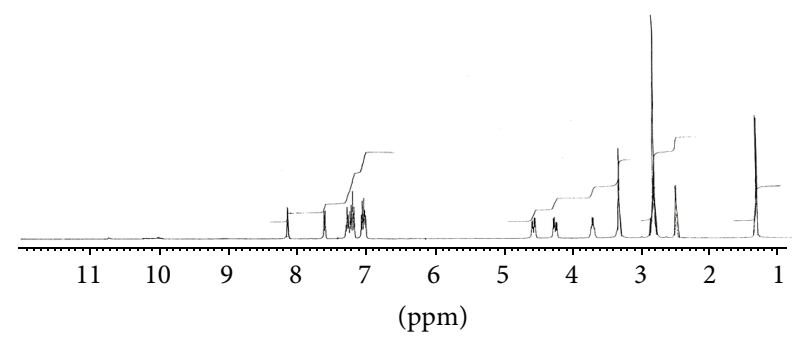

(b)

Figure 2: ${ }^{1} \mathrm{H}-\mathrm{NMR}$ spectra of (a) ligand IPH and (b) complex 3. 
niobium complexes, no change occurs at $\delta 1.31 \mathrm{ppm}$ and at $\delta 6.78-7.8 \mathrm{ppm}$ assigned to alkyl and aromatic protons, respectively. In complex 1 the signals at around $\delta 2.85$ and at $\delta$ $3.33 \mathrm{ppm}$ indicate a downfield shift of alkyl protons attached to the secondary nitrogen and heterocyclic nitrogen, thereby suggesting the involvement of secondary nitrogen as well as heterocyclic nitrogen atoms in coordination with niobium ion.

3.5. Thermogravimetric Study. The decomposition temperature of the complexes obtained from their thermograms and the data are presented in Table 4, and the thermograms of complexes $\mathbf{1}$ and $\mathbf{4}$ are depicted in Figure 3. Thermogravimetric study indicates that all the complexes are thermally stable up to $220^{\circ} \mathrm{C}$ and the decomposition of the complexes takes place in two steps, namely, decomposition of organic moiety and the loss of tartrate followed by the formation of $\mathrm{Nb}_{2} \mathrm{O}_{5}$ in the temperature ranges $220-330$ and $330-555^{\circ} \mathrm{C}$, respectively. The decomposition was slow in the beginning but rapid in later. The complexes attained constant weight between 600 and $700^{\circ} \mathrm{C}$. The weight observed in each case was in full agreement with the weight loss calculated on the basis of the stoichiometry proposed for the complexes. From the previous spectral and thermal data, an octahedral structure for niobium(V) complexes was predicted in Figure 4.

3.6. Evaluation of Antimicrobial Activity. The ligands $\mathrm{DMH}$, IMH, IPH, FPH, and TMT and their niobium(V) complexes were screened separately for both antibacterial and antifungal activities. The average percentage inhibition of both bacterial and fungicidal growth media compared to the respective controls was calculated by using the Vincent equation [24]. The screening data of average percentage inhibition of bacteria and the fungi at $30 \mu \mathrm{g}$ and at $60 \mu \mathrm{g}$ concentrations are given in Tables 5 and 6.

The results clearly indicate that the complexes have both antibacterial and antifungal activities against the tested organisms. The results of the inhibitory activity of the synthesized complexes on the organisms show that in lower concentration the complex did not affect much on the bacterial and fungal growth. It shows that as the concentration of the complex increases, the inhibition of bacterial and fungal growth also increases. The screening of data reveals that the niobium $(\mathrm{V})$ complexes show greater antimicrobial activity compared to the free ligands. A possible explanation for the toxicity may be explained by chelation theory [25]. It was suggested that chelation reduces the polarity of the metal ion considerably mainly because its positive charge is partially shared with donor atoms and $\pi$-electron delocalization over the whole chelating ring that is feasible. This increases the lipophilic character of the metal chelates, which favours its permeation through lipoid layers of the organism membranes.

\section{Conclusions}

The molar conductance data indicate the $1: 1$ electrolytic nature of the newly prepared niobium(V) complexes. TG
TABLE 4: Thermogravimetric data for niobium(V) complexes.

\begin{tabular}{|c|c|c|c|c|}
\hline \multirow{2}{*}{ Complex } & \multirow{2}{*}{$\begin{array}{c}\text { Temp. range } \\
\left({ }^{\circ} \mathrm{C}\right)\end{array}$} & \multicolumn{2}{|c|}{ Weight loss (\%) } & \multirow{2}{*}{ Probable product } \\
\hline & & Found & Calc. & \\
\hline \multirow{2}{*}{1} & $235-330$ & 79.55 & 81.89 & {$\left[(\mathrm{DM})_{2}\left(\mathrm{C}_{4} \mathrm{H}_{4} \mathrm{O}_{6}\right)_{3}\right]$} \\
\hline & $360-540$ & 19.32 & 22.35 & $\mathrm{Nb}_{2} \mathrm{O}_{5}$ \\
\hline \multirow{2}{*}{2} & $255-315$ & 79.78 & 82.18 & {$\left[(\mathrm{IM})_{2}\left(\mathrm{C}_{4} \mathrm{H}_{4} \mathrm{O}_{6}\right)_{3}\right]$} \\
\hline & $340-515$ & 19.03 & 21.78 & $\mathrm{Nb}_{2} \mathrm{O}_{5}$ \\
\hline \multirow[t]{2}{*}{3} & $250-325$ & 80.23 & 82.32 & {$\left[(\mathrm{IP})_{2}\left(\mathrm{C}_{4} \mathrm{H}_{4} \mathrm{O}_{6}\right)_{3}\right]$} \\
\hline & $345-520$ & 18.82 & 21.59 & $\mathrm{Nb}_{2} \mathrm{O}_{5}$ \\
\hline \multirow{2}{*}{4} & $255-320$ & 82.88 & 84.48 & {$\left[(\mathrm{FP})_{2}\left(\mathrm{C}_{4} \mathrm{H}_{4} \mathrm{O}_{6}\right)_{3}\right]$} \\
\hline & $330-550$ & 16.75 & 18.97 & $\mathrm{Nb}_{2} \mathrm{O}_{5}$ \\
\hline \multirow[t]{2}{*}{5} & $250-320$ & 80.18 & 82.67 & {$\left[(\mathrm{TM})_{2}\left(\mathrm{C}_{4} \mathrm{H}_{4} \mathrm{O}_{6}\right)_{3}\right]$} \\
\hline & $345-525$ & 18.29 & 21.14 & $\mathrm{Nb}_{2} \mathrm{O}_{5}$ \\
\hline
\end{tabular}

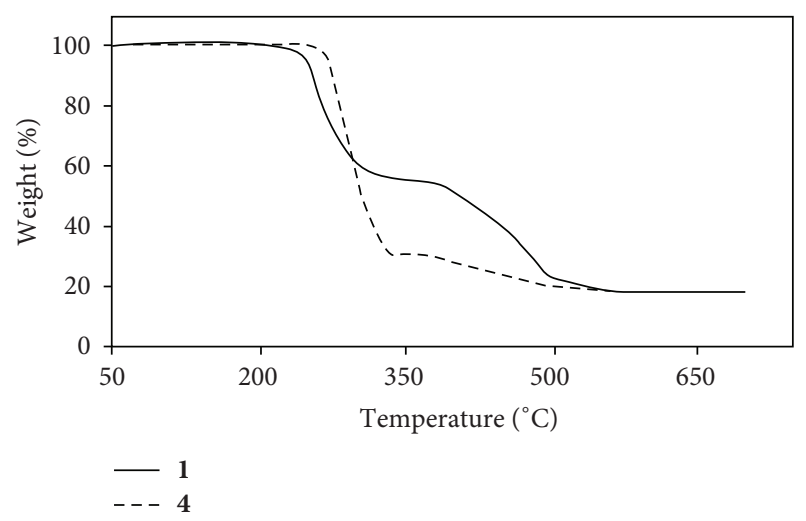

Figure 3: TGA curve of complexes 1 and 4.

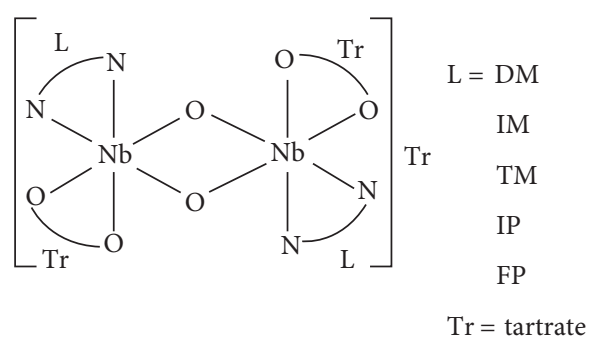

FIGURE 4: Suggested structure of the prepared complexes (1-5).

studies suggest that all complexes decompose in two steps, and finally they form their respective metal oxides. Based on chemical composition and physico-chemical studies, a sixcoordinated dioxobridged binuclear structure has been proposed tentatively for niobium(V) complexes. The antimicrobial activity screened for the studied complexes against tested bacteria and fungi shows that niobium complexes display greater microbial toxicity compared to the free ligands. 
TABLE 5: Antibacterial screening data of the ligands and their metal complexes.

\begin{tabular}{|c|c|c|c|c|c|c|c|c|}
\hline \multirow{3}{*}{ Compound } & \multicolumn{8}{|c|}{ Percentage inhibition zone $( \pm)^{\mathrm{a}}$} \\
\hline & \multicolumn{2}{|c|}{ S. aureus } & \multicolumn{2}{|c|}{ E. coli } & \multicolumn{2}{|c|}{ P. aregainosa } & \multicolumn{2}{|c|}{ B. subtilius } \\
\hline & $30 \mu \mathrm{g}$ & $60 \mu \mathrm{g}$ & $30 \mu \mathrm{g}$ & $60 \mu \mathrm{g}$ & $30 \mu \mathrm{g}$ & $60 \mu \mathrm{g}$ & $30 \mu \mathrm{g}$ & $60 \mu \mathrm{g}$ \\
\hline $\mathrm{DMH}$ & 0.0 & 8.5 & 0.0 & 7.4 & 0.0 & 6.0 & 0.0 & 10.2 \\
\hline $\mathrm{IMH}$ & 4.4 & 9.7 & 2.6 & 11.5 & 8.2 & 14.7 & 2.8 & 9.2 \\
\hline IPH & 2.7 & 8.7 & 2.2 & 9.2 & 2.4 & 7.4 & 1.2 & 9.3 \\
\hline $\mathrm{FPH}$ & 0.0 & 6.2 & 0.0 & 7.4 & 0.0 & 5.9 & 0.0 & 16.0 \\
\hline TMT & 0.0 & 5.4 & 0.0 & 8.3 & 0.0 & 7.5 & 0.0 & 14.2 \\
\hline 1 & 8.2 & 19.0 & 6.7 & 22.4 & 8.9 & 22.8 & 6.8 & 21.6 \\
\hline 2 & 7.6 & 17.4 & 3.5 & 16.8 & 7.5 & 23.3 & 6.7 & 20.3 \\
\hline 3 & 9.2 & 33.2 & 10.5 & 36.2 & 7.0 & 27.3 & 8.9 & 26.4 \\
\hline 4 & 6.3 & 13.1 & 4.5 & 18.2 & 4.7 & 16.4 & 5.3 & 20.6 \\
\hline 5 & 5.3 & 11.2 & 4.5 & 16.0 & 4.4 & 15.0 & 5.5 & 16.5 \\
\hline Chloramphenicol & 100 & 100 & 100 & 100 & 100 & 100 & 100 & 100 \\
\hline
\end{tabular}

DMSO showed no inhibition, ${ }^{\text {a }}$ each value is the average of four replicates.

TABLE 6: Antifungal screening data of the ligands and their metal complexes.

\begin{tabular}{lcccc}
\hline \multirow{2}{*}{ Compound } & \multicolumn{3}{c}{ Percentage inhibition zone $( \pm)^{\mathrm{a}}$} \\
& $30 \mu \mathrm{g}$ & $60 \mu \mathrm{g}$ & $30 \mu \mathrm{g}$ & $60 \mu \mathrm{g}$ \\
\hline $\mathrm{DMH}$ & 0.0 & 5.2 & 0.0 & 8.6 \\
$\mathrm{IMH}$ & 3.6 & 3.2 & 5.6 & 12.5 \\
$\mathrm{IPH}$ & 13.4 & 28.4 & 10.2 & 27.5 \\
FPH & 0.0 & 5.4 & 0.0 & 8.3 \\
TMT & 2.0 & 10.2 & 2.0 & 17.6 \\
$\mathbf{1}$ & 8.2 & 23.3 & 9.6 & 27.2 \\
$\mathbf{2}$ & 7.3 & 27.3 & 6.2 & 30.7 \\
$\mathbf{3}$ & 13.5 & 38.4 & 14.8 & 34.6 \\
$\mathbf{4}$ & 4.2 & 11.7 & 5.3 & 13.9 \\
$\mathbf{5}$ & 3.5 & 17.3 & 4.7 & 16.5 \\
Griseofulvin & 100 & 100 & 100 & 100 \\
\hline
\end{tabular}

DMSO showed no inhibition, ${ }^{\text {a }}$ each value is the average of four replicates.

\section{Acknowledgment}

The authors are thankful to the University of Mysore, Mysore, India for providing financial assistance through a minor research project.

\section{References}

[1] M. T. Tanvir, Y. Aoki, and H. Habazaki, "Improved electrical properties of silicon-incorporated anodic niobium oxide formed on porous Nb-Si substrate," Applied Surface Science, vol. 255, no. 20, pp. 8383-8389, 2009.

[2] H. Smogor, T. Cardinal, V. Jubera et al., "Effect of silver on phase separation and crystallization of niobium oxide containing glasses," Journal of Solid State Chemistry, vol. 182, no. 6, pp. 1351-1358, 2009.
[3] A. M. R. Galletti and G. Pampaloni, "Niobium complexes as catalytic precursors for the polymerization of olefins," Coordination Chemistry Reviews, vol. 254, no. 5-6, pp. 525-536, 2010.

[4] A. Godeke, A. den Ouden, A. Nijhuis, and H. H. J. ten Kate, "State of the art powder-in-tube niobium-tin superconductors," Cryogenics, vol. 48, no. 7-8, pp. 308-316, 2008.

[5] M. E. Campderrós and J. Marchese, "Transport of niobium(V) through a TBP-Alamine 336 supported liquid membrane from chloride solutions," Hydrometallurgy, vol. 61, no. 2, pp. 89-95, 2001.

[6] L. Dongling, H. Xiaoyan, and W. Haizhou, "Separation and simultaneous determination of niobium and tantalum in steel by reversed-phase high-performance liquid chromatography using 2-(2-pyridylazo)-5-diethylamino phenol as a pre-column derivatizing reagent," Talanta, vol. 63, no. 2, pp. 233-237, 2004.

[7] H. Najafi, J. Rassizadehghani, and S. Asgari, "As-cast mechanical properties of vanadium/niobium microalloyed steels," Materials Science and Engineering A, vol. 486, no. 1-2, pp. 1-7, 2008.

[8] M. Sankar, Y. S. Reddy, and R. G. Baligidad, "Effect of different thermomechanical processing on structure and mechanical properties of electron beam melted niobium," Transactions of the Indian Institute of Metals, vol. 62, no. 2, pp. 135-139, 2009.

[9] H. Thomadaki, A. Lymberopoulou-Karaliota, A. Maniatakou, and A. Scorilas, "Synthesis, spectroscopic study and anticancer activity of a water-soluble $\mathrm{Nb}(\mathrm{V})$ peroxo complex," Journal of Inorganic Biochemistry, vol. 105, pp. 155-163, 2011.

[10] E. Melendez, "Metallocenes as target specific drugs for cancer treatment," Inorganica Chimica Acta, vol. 393, pp. 36-52, 2012.

[11] A. M. Elsome, J. M. T. Hamilton-Miller, W. Brumfitt, and W. C. Noble, "In-vitro and in-vivo antibacterial activity of plaunotol, a cytoprotective antiulcer agent, against Helicobacter pylori," Journal of Antimicrobial Chemotherapy, vol. 37, no. 5, pp. 919-929, 1996.

[12] Y. Shi, I. Harvey, D. Campopiano, and P. J. Sadler, "Niobium uptake and release by bacterial ferric ion binding protein," Bioinorganic Chemistry and Applications, no. 14, pp. 1-11, 20102010.

[13] B. Keshavan and H. Kempe Gowda, "Synthesis, spectral andfungicidal studies on dioxobridged binuclear niobium(V) and tantalum(V) complexes of N-alkylphenothiazines," Turkish Journal of Chemistry, vol. 26, no. 2, pp. 237-243, 2002. 
[14] A. R. Katritzky and A. J. Boulton, Advances in Heterocyclic Chemistry, vol. 9, Academic Press, New York, NY, USA, 1968.

[15] A. I. Vogel, A Text Book of Quantitative Inorganic Analysis, ELBS and Longman, London, UK, 3rd edition, 1975.

[16] A. L. Barry, "Procedure for testing antimicrobial agents in agar media. Theoretical consideration," in Antibiotics in Laboratory Medicine, V. Lorian, Ed., p. 1, Williams and Wilkins, London, UK, 2nd edition, 1980.

[17] J. Bateman, R. D. Chapman, and D. Simpson, "Possible toxicity of herbal remedies," Scottish Medical Journal, vol. 43, no. 1, pp. 7-15, 1998.

[18] F. A. Cotton, M. P. Diebold, and W. J. Roth, "Binuclear alkoxide complexes of niobium and tantalum in lower oxidation states," Inorganic Chemistry, vol. 24, no. 22, pp. 3509-3510, 1985.

[19] A. P. Mishra, A. Tiwari, S. K. Gupta, and R. Jain, "synthesis, spectral and antimicrobial studies of some $\mathrm{Co}(\mathrm{II}), \mathrm{Ni}(\mathrm{II})$ and $\mathrm{Cu}(\mathrm{II})$ complexes containing 2-thiophenecarboxaldehyde moiety," E-Journal of Chemistry, vol. 9, no. 3, pp. 1113-1121, 2012.

[20] R. M. Issa, A. M. Khedr, and H. Rizk, "1 H NMR, IR and UV/VIS spectroscopic studies of some schiff bases derived From 2aminobenzothiazole and 2-amino-3-hydroxypyridine," Journal of the Chinese Chemical Society, vol. 55, no. 4, pp. 875-884, 2008.

[21] M. Senthilkumar and C. Ramachandraraja Growth, "Structural, spectral and optical studies on pure and L-alanine mixed bisthiourea cadmium bromide (LABTCB) crystals," Journal of Minerals \& Materials Characterization \& Engineering, vol. 11, no. 6, pp. 631-639, 2012.

[22] M. M. Alam, S. M. M. Rahman, M. M. Rahman, and S. M. S. Islam, "Simultaneous preparation of facial and meridional isomer of cobalt-amino acid complexes and their characterization," Journal of Scientific Research, vol. 2, no. 1, pp. 91-98, 2010.

[23] E. N. Nfor, S. N. Esemu, G. A. Ayimele, E. A. Eno, G. E. Iniama, and O. E. Offiong, "Synthesis, stereochemistry and antimicrobial activity of copper(II) and nickel(II) complexes of 4-phenylsemicarbazones," Bulletin Chemical Society of Ethiopia, vol. 25, no. 3, pp. 361-370, 2011.

[24] J. H. Kim, K. L. Chan, N. Mahoney, and B. C. Campbell, "Antifungal activity of redox-active benzaldehydes that target cellular antioxidation," Annals of Clinical Microbiology and Antimicrobials, vol. 10, pp. 23-39, 2011.

[25] M. A. Neelakantan, M. Esakkiammal, S. S. Mariappan, J. Dharmaraja, and T. Jeyakumar, "Synthesis, characterization and biocidal activities of some schiff base metal complexes," Indian Journal of Pharmaceutical Sciences, vol. 72, no. 2, pp. 216-222, 2010. 

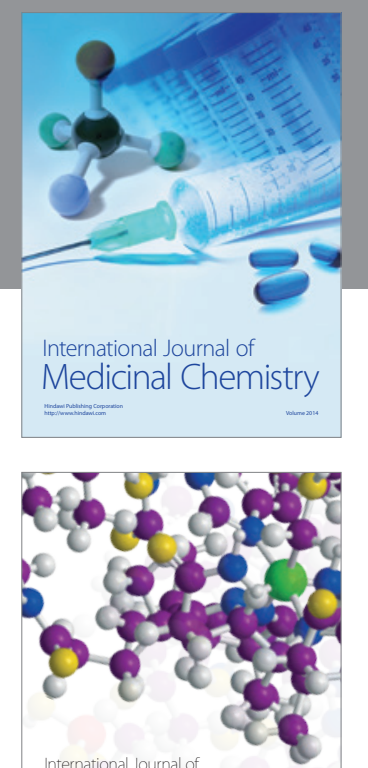

\section{Carbohydrate} Chemistry

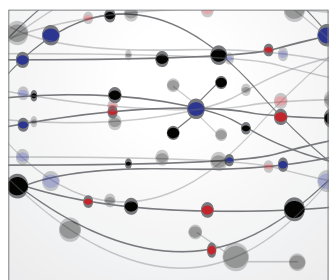

The Scientific World Journal
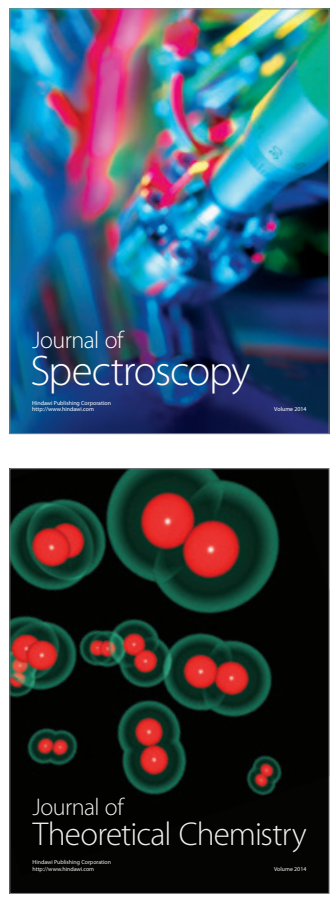
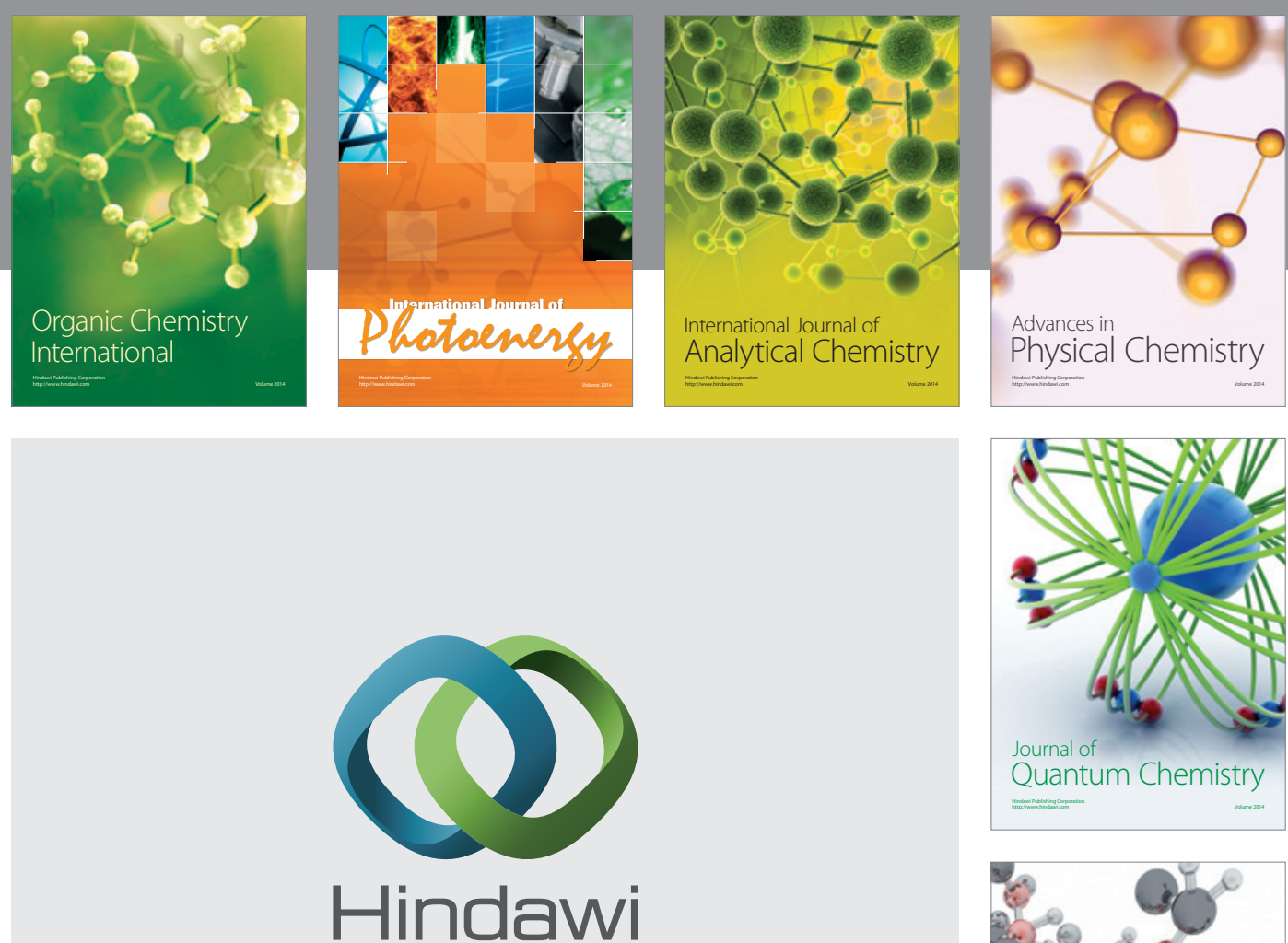

Submit your manuscripts at

http://www.hindawi.com

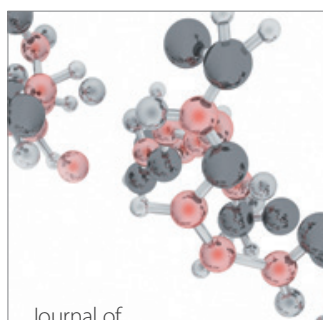

Analytical Methods

in Chemistry

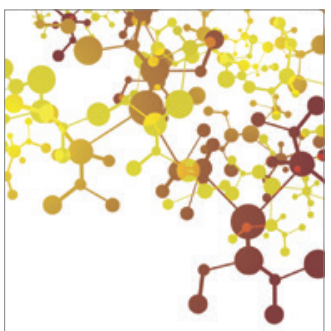

Journal of

Applied Chemistry

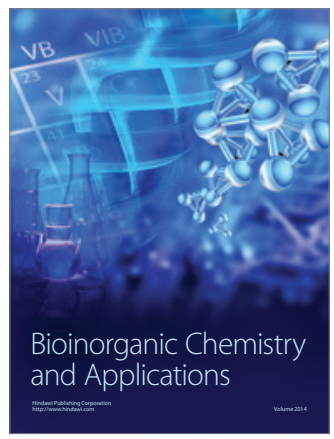

Inorganic Chemistry
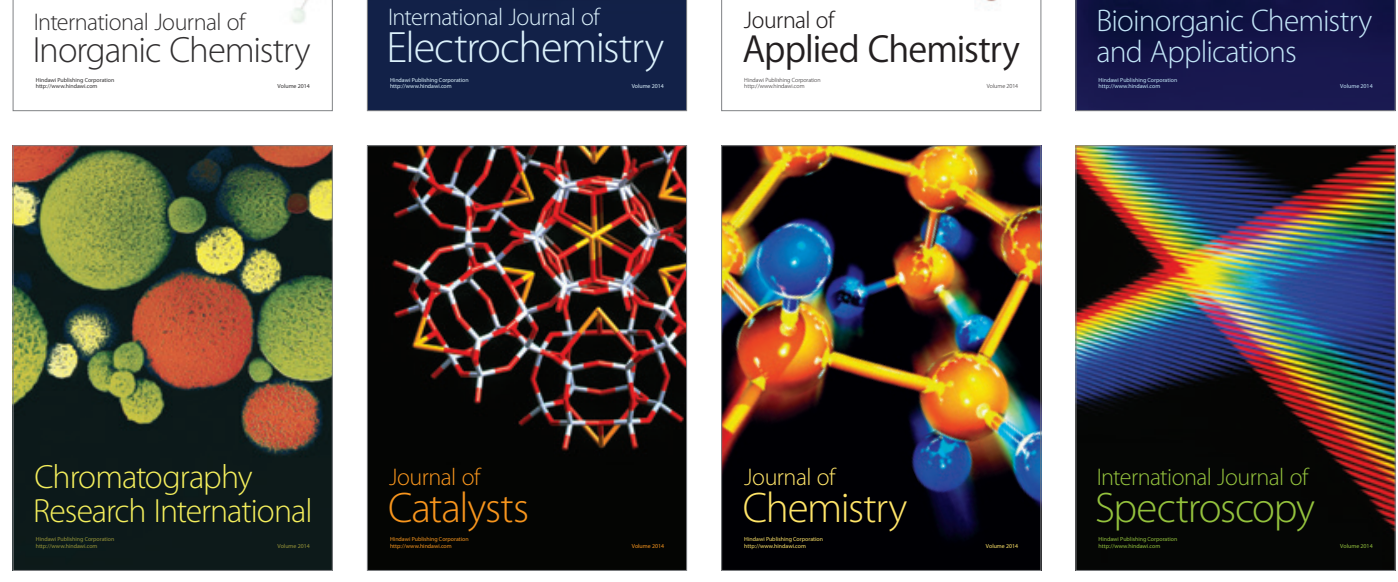